DOI: 10.34031/2618-7183-2021-4-1-5-17

Alfimova N.I. *, Candidate of Engineering Sciences (Ph.D.), Associate Professor, Pirieva S.Yu., Belgorod State Technological University named after V.G. Shukhov, Russia, Titenko A.A., Engineering Center NRU "BelSU", Russia *Corresponding author E-mail: alfimovan@mail.ru

\title{
UTILIZATION OF GYPSUM-BEARING WASTES IN MATERIALS OF THE CONSTRUCTION INDUSTRY AND OTHER AREAS
}

\begin{abstract}
: rational environmental management is one of the priorities of the technological development of the Russian Federation and most countries of the world. Particularly important in this area is the work undertaken with previously generated and accumulated waste, a whole group of which is gypsum-bearing wastes (GBW), which includes by-products of various industries: phosphogypsum, borogypsum, chlorogypsum, ferrogypsum, citrogypsum, vitamin gypsum, etc. GBW features are similar compositions, prevalence, perennial volumes of stored reserves with stable dynamics of annual growth. This determines the relevance of research on the development of a unified methodology for converting GBW of various types into target products particularly for construction purposes, providing maximum energy efficiency and minimal generation of secondary waste. The starting point of the research is the monitoring of approaches developed by the scientific community which are presented in the article. It is shown that researchers are exploring several main areas of GBW conversion: components of Portland cement and clinker; single and multicomponent binders; direct raw materials for the production of building materials; and road construction. The latter two directions have the greatest potential capacity for the consumption of GBW. The general level of research on the issue is not exhaustive, but has the potential to improve on existing methods of processing and application and promote the search for new and more efficient methods.

Keywords: gypsum-bearing wastes, phosphogypsum, borogypsum; citrogypsum, gypsum $\alpha$-hemihydrate, gypsum $\beta$-hemihydrate, cement, mortars

\section{Introduction}

Gypsum-bearing wastes (GBW) and methods for their disposal through the use of building materials as raw materials have been the subject of research by various scientific groups around the world for several decades. The increased activity of researchers, naturally, is recorded in areas of the greatest concentration of such products. This is due to their significant negative impact on the ecology and economy of the territories of those locations, which in many cases impedes the development of settlements, industrial facilities and infrastructure facilities.

Currently, more than 50 types of GBW are known, which are by-products of various industries (phosphogypsum, borogypsum, chlorogypsum, ferrogypsum, citrogypsum, vitamin gypsum, etc.) [1]. Despite significant differences in chemical compositions and methods of formation, a unifying aspect for all such products is the predominant content of calcium sulfates. This creates the prerequisites for the possibility of developing a unified approach for the transformation of GBW into various useful products, taking into account the individual characteristics of each type of raw material.

The aim of this work is to summarize the global experience in the use of gypsum-bearing wastes in the construction materials industry as a starting point for developing a broad-functional algorithm for processing that waste. The results of the analysis are grouped in the main areas of usage of GBW.

There is no single set of statistics on world volumes of current education of all types of gypsum-bearing wastes and accumulated reserves. However, open data on phosphogypsum can serve as a clear illustration of the magnitude of the problem. Phosphogypsum, a by-product of the production of phosphate fertilizers and phosphoric acid, is the most large-scale example of gypsum-bearing wastes. This is due to the fact that the extraction and processing of phosphates is carried out in many countries (fig. 1). Moreover, it is predicted that the global consumption of $\mathrm{P}_{2} \mathrm{O}_{5}$ contained in phosphoric acid, fertilizers and other products will increase from 47 million tons in 2019 to 50 million tons in 2023 and consequently the amount of phosphogypsum will also increase [2].
\end{abstract}




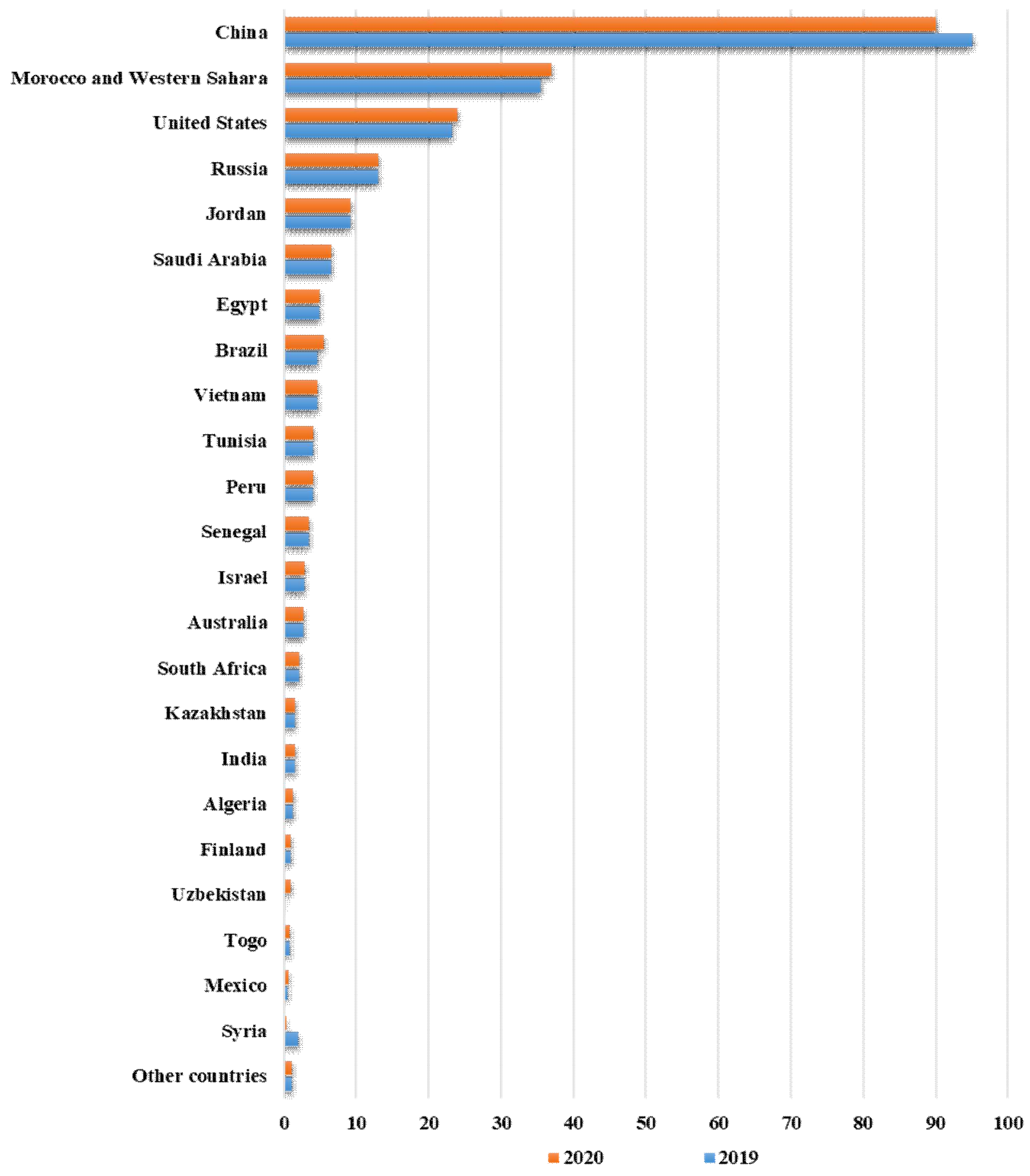

Fig 1. Phosphate production (million tons) [2]

Currently, according to average estimates, the applied industrial technologies for the production of phosphate fertilizers produce 4-6 tons of phosphogypsum for each ton of phosphoric acid produced [3]. Moreover, most phosphogypsum, as well as other gypsum-bearing waste, is not immediately processed but accumulates over many years in dumps or artificial reservoirs which leads to serious pollution of the environment, soil, water and atmosphere [1, $3,4]$. By volume, these products can be considered as a comprehensive alternative to natural raw materials, the production of which is significantly inferior to the number of annual GBW. 


\section{Methodology}

The review was carried out by processing, analysis, and integration of data from open literary sources, which are presented on the portal "Scientific electronic library eLIBRARY.RU"; collections of full-text journals by Elsevier, based on the ScienceDirect platform; as well as the Google Scholar search system.

\section{Discussion \\ 3.1. Cement industry}

When studying existing methods for the industrial use of GBW, analysis of literary sources showed that most often gypsum-bearing wastes, including phosphogypsum, are considered a component of the raw material charge in the production of special types of cement clinker or setting regulator (retarder) in traditional Portland cement [513].

Thus, the authors of [5] studied the effect of $\mathrm{P}_{2} \mathrm{O}_{5}$ and $\mathrm{F}$ impurities contained in phosphogypsum on the formation of clinker of the belite calcium sulfoaluminate (BCSA) composition and cement hydration based on it. It was found that the replacement of natural gypsum with phosphogypsum helps to reduce the sintering temperature of the raw material mixture by $50{ }^{\circ} \mathrm{C}$, however, impurities reduce the reactivity of $\mathrm{C}_{4} \mathrm{~A}_{3} \mathrm{~S}^{-}$during hydration of BCSA cement and its compressive strength at 6 hours, 12 hours and 1 day. When phosphogypsum was introduced as an additive to cement, an increase in setting time was revealed, which the authors explain by the presence of soluble fluorine impurity, which can also inhibit $\mathrm{C}_{4} \mathrm{~A}_{3} \mathrm{~S}^{-}$and reduce the compressive strength of cement.

The authors of [6] found that the addition of $10 \%$ phosphogypsum to the raw mix reduces the clinker burning temperature from $1470{ }^{\circ} \mathrm{C}$ to $1200{ }^{\circ} \mathrm{C}$, which in turn contributes to an increase in the efficiency of the cement plant by $25 \%$ and increases the life of the kilns. Structural-morphological analysis of clinker obtained using phosphogypsum showed the presence of low-dimensional crystals of $\mathrm{C}_{3} \mathrm{~S}$ and $\mathrm{C}_{2} \mathrm{~S}$, generating a large number of inclusions that positively affect the properties of cement.

Numerous studies have also proved the feasibility of using phosphogypsum which is purified of its impurities as a setting regulator (moderator) in cement production. Hence, the authors of [7] cite data according to which the dosage of $5-10 \%$ of washed and subsequently dried phosphogypsum (Republic of Bangladesh) in cement is a perfectly acceptable alternative to natural gypsum stone. The authors of [8] found that pretreatment of ph osphogypsum $\mathrm{Ca}(\mathrm{OH})_{2}$ and $\mathrm{Al}_{2}\left(\mathrm{SO}_{4}\right)_{3}$ neutralizes the action of harmful impurities and makes it suitable for the production of sulfoaluminate cement.

Taher [9] also confirmed the positive effect of calcination on the properties of phosphogypsum. In particular, that author showed that the introduction of $6 \%$ heat-treated phosphogypsum into the composition of slag Portland cement contributes to an improvement in the hydration process.

Ozkul [10] investigated the possibility of using citro- (Izmit, Turkey) and desulfogypsum (Cayirhan Powerplant, Ankara, Turkey) in powder form and also agglomerated under pressure as cement hardening agents. Both gypsumbearing wastes were preliminarily dried at a temperature of $40{ }^{\circ} \mathrm{C}$; samples made using natural gypsum stone acted as a control. The setting time, the change in the volume of cement paste, as well as the compressive and flexural strength of cement mortars aged 3, 7, and 28 days were used as control parameters. An analysis of the results showed that the use of citro- and desulfogypsum as cement setting retarders is quite acceptable. At the same time, the mixture with citrogypsum was notable for some retardation of the setting in the initial period, and desulfogypsum increased the end of setting time by 1 hour. The bending strength at all ages of the samples with gypsumbearing wastes did not differ significantly from the control, however, the powdery desulfogypsum caused a slight decrease in compressive strength at an early age. Using it in an agglomerated state contributed to the increase in strength of the performance of control samples. The compressive strength of samples made using agglomerated citrogypsum comparable to the control except for at 3 days, where a discharge was recorded. In general, the author concluded that citro- and desulfogypsum can be used as cement setting regulators.

Bensted [11] considered the possibility of using citro-, boro- and desulfogypsum as a setting retarder and compared them with natural retarders. Results of the study showed that during hydration of cement containing boron and cytogypsum, much more ettringite is formed than during hydration of cement with desulfuric and natural gypsum.

Elbeyli et al. [12] present the results of their study regarding the possibility of using conventional and calcined borogypsum as an additive to cement. Calcination was carried out by heating to $500{ }^{\circ} \mathrm{C}$ by raising the temperature by $10{ }^{\circ} \mathrm{C}$ every minute. Then borogypsum $(5 \%$ and $7 \%)$, hemihydrate borogypsum $(5 \%)$ and natural gypsum $(5 \%)$ were ground together with Portland cement clinker. The determination of the setting time, compressive strength, and fineness of grinding according to the European standard (EN 196) made it possible to establish that an increase from 5\% to 7\% in the content of borogypsum in Portland cement is accompanied by an increase in setting time and 
a decrease in compressive strength. Cement prepared with borogypsum (5\%) not subjected to calcination has the same strength properties as a traditional composition with natural gypsum. At the same time, the composition containing $5 \%$ of the hemihydrate obtained by calcination has a $25 \%$ increased compressive strength at the age of 28 days.

In the study by Sevim et al. [13], boribypsum from the Etibor Emet boric acid plant (Turkey) was introduced into cement in the amount of 3\%,5\%,10\% and $15 \%$. During the study, it was found that borogypsum increases the setting time of cement, and reduces the volume expansion and mobility of the mixture. A binder containing 3\% and $5 \%$ borogypsum is more compressive and tensile in comparison with the control. Samples containing $10 \%$ borogypsum reached the compressive strength of control samples at the age of 90 days, and samples with $15 \%$ borogypsum showed lower strength compared to the non-additive procedure.

\subsection{Plaster binders}

Another large-scale direction for the disposal of gypsum-bearing wastes is their use as raw materials for the production of gypsum binders. However, it should be noted that the use of traditional technologies that are used to obtain binders from natural gypsum stone in the case of using technogenic raw materials is not always effective. This is due to several factors among which can be distinguished:

- high dispersion of raw materials;

- increased humidity, which can reach $60 \%$;

- inconstancy of the material composition, including within the same storage;

- the presence of a large number of impurities.

All these factors, both individually and in aggregate, affect the production technology and processing parameters of raw materials and as a rule negatively affect the quality of the final product and products based on it. This also serves as a motivator for a large number of scientific studies aimed at improving existing and developing alternative methods for the synthesis of binders from gypsum-bearing wastes.

The efficiency of using the autoclave method in the synthesis of high-quality $\alpha$-modification binders from natural raw materials has been known for a long time and therefore this method has been tested using industrial waste.

In the study by Yang et al. [14], the possibility of obtaining a binder from phosphogypsum formed during the production of phosphoric acid (plant in Xiangfan, Hubei Province, China) was considered in two modes: by treating with low-pressure steam $-0.12 \mathrm{MPa}, 120{ }^{\circ} \mathrm{C}$ for 16 hours, as well as at a higher pressure of $0.8 \mathrm{MPa}$ and a temperature of $180{ }^{\circ} \mathrm{C}$ for 8 hours. After autoclaving, the samples were aged for 24 hours with ethanol. An analysis of the obtained binders showed that when using the first mode, the crystalline phase basically turned from hemihydrate to dihydrate, while the use of the second mode contributed to complete dehydration with the transition of twowater gypsum to anhydrite. The synthesis of a binder in this case is based on classical technology, however, there are a number of patents in which the authors propose to obtain a binder under conditions of high pressure and temperature using a number of additional measures.

In particular, the patent of Myasnikov et al. [15] proposes a method for producing a binder from a citrogypsum by recrystallization in an autoclave. In this case, the waste is preliminarily subjected to repulpation, then it goes through the stage of purification by the method of reagentless flotation under the influence of polyacrylamide. A mixture of copper sulfate and sodium sulfate is added to the resulting pulp in a ratio of 1:2 in an amount of 1.2-1.5 $\mathrm{kg} / \mathrm{m}^{3}$ and sent to an autoclave. In this way, depending on the amount of sulfates introduced $\left(\mathrm{CuSO}_{4}+\mathrm{Na}_{2} \mathrm{SO}_{4}\right.$ mixture), the authors synthesized binders with bending strength of 3.4-5.4 MPa and 5.8-12.5 MPa at two hours of age under compression. This method acted as a prototype for the development of a method for producing a binder from borogypsum [16]. At the same time, an improved process sequence includes the repulpation of raw materials; recovering calcium sulfate dihydrate by flotation into a foam product; dehydration of $\mathrm{CaSO}_{4} \cdot 2 \mathrm{H}_{2} \mathrm{O}$ in an autoclave after treatment with sulfuric acid and calcium hydroxide in the range of $\mathrm{pH} 2-7$. As a flotation agent, a mixture of sodium salts of fatty acids (sodium oleate, sodium stearate, sodium palmetate) and liquid sodium glass in certain proportions was used.

The possibility of obtaining high-strength binders is studied in [17] and those authors propose a technology for neutralizing phosphogypsum impurities at the JSC Gomel Chemical Plant (Gomel, Belarus), followed by the synthesis of $\alpha$ - and $\beta$-calcium sulfate hemihydrate. The technological process of purification consists of three stages: first, lime milk is introduced into phosphogypsum (1-1.5\% CaO by weight of phosphogypsum); second, a suspension of phosphogypsum is passed through a wet grinding mill; third, conditioning when pressing dried to a moisture content of 5-7\% phosphogypsum. Further, depending on the need to obtain one or another modification of the binder, a thermal unit for dehydration is selected. The authors note the possibility of obtaining a knitting grade from G-7 to $\mathrm{G}-13$ and higher when using autoclaves. 
The production of binders at elevated temperatures and atmospheric pressure (autoclave-free technology) is also considered in the works of various researchers $[17,18]$. However, it should be noted that for all the simplicity and attractiveness of the technology, even through the use of various additional techniques, this method can only produce astringent $\beta$-modifications.

To obtain $\alpha$-hemihydrate from gypsum-bearing wastes, the salt solution method is often considered [19-25]. In this case, dehydration is carried out in a solution of salts $\left(\mathrm{Na}_{2} \mathrm{SO}_{4}\right.$ [19], $\mathrm{CaCl}_{2}, \mathrm{MgCl}_{2}, \mathrm{KCl}$ [20-25], etc.) at elevated temperatures up to $97{ }^{\circ} \mathrm{C}$ in the presence of various modifiers (maleic acid, L-aspartic acid, sodium succinate, potassium sodium tartrate, sodium citrate, etc.), which provide the synthesis of binder crystals with the necessary morphology, making it possible to obtain gypsum stone with physicomechanical characteristics that meet the requirements of standards. In the process of synthesis of a binder, the morphology of neoplasms is constantly monitored by periodic sampling. At the final stage of the process, filtration is carried out, the filtrate is washed with water and pure ethanol and dried at a temperature of $60-80{ }^{\circ} \mathrm{C}$. Moreover, it is possible to synthesize a binder in salt solutions both at atmospheric [19-24] and at elevated pressure [25]. Additionally, the quality of binders can be improved by preliminary purification of phosphogypsum from impurities [22].

There is also a method for the synthesis of high-quality binders from gypsum-bearing wastes using sulfuric acid [26-30]. The essence of this method is the dehydration of citrogypsum in a solution of sulfuric acid, followed by treatment with $\mathrm{CaO}$. The binder obtained during the dehydration reaction is represented by hemihydrate of calcium sulfate and anhydrite the content of which, in the system, depends on the initial temperature of the feed and the ratio of $\mathrm{H}_{2} \mathrm{SO}_{4} \cdot \mathrm{H}_{2} \mathrm{O}$. The authors of the development note the possibility of obtaining a binder in this way with a strength of up to $30 \mathrm{MPa}$. This method was also obtained gypsum binder from phosphogypsum (Goebes, Tunisia) with a redistribution of strength in the range 6-10 MPa at the age of 28 days [31].

It should be noted that the synthesis of binders from gypsum-bearing wastes using salt solutions and acids is characterized by reduced energy consumption compared to an autoclave, however to ensure the technological process a large number of chemicals and tight control of the synthesis process are required. In addition, the use of sulfuric acid creates dangerous working conditions and contributes to the rapid deterioration of equipment.

The advantages and disadvantages of the considered methods are summarized in Table 1 [32].

Advantages and non-deliveries of methods for the production of gypsum binders from industrial wastes

\begin{tabular}{|l|l|l|}
\hline \multicolumn{1}{|c|}{ Production Method } & \multicolumn{1}{|c|}{ Advantages } & \multicolumn{1}{c|}{ Disadvantages } \\
\hline Autoclave & $\begin{array}{l}\text { Possibility of obtaining a high-strength } \\
\text { binder }(\alpha \text {-hemihydrate) }\end{array}$ & $\begin{array}{l}\text { High energy costs, the need for spe- } \\
\text { cial equipment, the duration of the } \\
\text { process }\end{array}$ \\
\hline Calcination method & $\begin{array}{l}\text { Availability of equipment, ease of pro- } \\
\text { duction }\end{array}$ & $\begin{array}{l}\text { The possibility of obtaining only } \\
\text { low-quality binder }(\beta \text {-hemihydrate) }\end{array}$ \\
\hline $\begin{array}{l}\text { Chemical method (sa- } \\
\text { line solutions, acids) }\end{array}$ & $\begin{array}{l}\text { Low energy consumption, the possibil- } \\
\text { ity of obtaining high-strength binder }(\alpha- \\
\text { hemihydrate) }\end{array}$ & $\begin{array}{l}\text { The need for chemicals, the com- } \\
\text { plexity of the process, phased control } \\
\text { and sampling, the creation of adverse } \\
\text { working conditions, rapid wear of } \\
\text { equipment }\end{array}$ \\
\hline
\end{tabular}

The specificity of gypsum-bearing wastes in all cases requires the use of special approaches and additional measures to obtain an astringent that meets the quality standards. Ultimately, the complexity of the technology negatively affects the cost of production and the profitability of its production in industrial volumes.

Numerous experts, whose studies were related to the production of binders from gypsum-bearing wastes, agree that the main technical problems are the low strength and water resistance of the products obtained. According to these indicators, binders based on GBW are significantly inferior to gypsum binders based on traditional natural raw materials, which makes direct competition difficult. One way to address these shortcomings is the creation of multicomponent systems in which gypsum-bearing wastes is used in both the processed and the natural form.

In particular, the possibility of modifying $\beta$-hemihydrate obtained from phosphogypsum (Yihua Fertilizer Inc., Hubei, China) with sulfoalluminate cement (SAC) was considered in [33]. The authors found that the introduction of $20 \% \mathrm{SAC}$ in the composition of $\beta$-hemihydrate promotes an increase in strength $(21.5 \mathrm{MPa})$ and an increase in the water resistance coefficient to 0.66 .

In [34], the authors showed the possibility of obtaining self-leveling floors with high physical and mechanical characteristics, consisting of a mixture of untreated phosphogypsum, Portland cement and sulfoaluminate cement. 
The possibility of increasing the efficiency of gypsum binders from gypsum-bearing wastes due to the creation of multicomponent systems was also confirmed in the work of Chernysh [35]. The objects of the study were gypsum binder obtained by the non-calcining method from wastes of citric acid production (Belgorod, Russia). In the study of various compositions, the author came to the conclusion that the composition is optimal: gypsum binder $60 \%$, cement M500 - 20\%, mineral additive (expanded clay dust) - 15\%, superplasticizer S-3 - 1.5\% (the remaining 3,5\% are substances that regulate rheological properties, as well as the kinetics of setting and hardening).

In [36], it is proposed to modify the binder directly in the manufacturing process under conditions of high pressure and temperature, by introducing citrogypsum into the pulp before heat treatment of polyacrylamide, which helps to reduce the gypsum ratio and improve the quality of the final products. Hence, a stone based on the obtained modified binder was characterized by high water resistance $(0.8)$.

\subsection{Building materials}

Romero-Hermida et al. [37] considered the possibility of producing putty from lime obtained by treating phosphogypsum (Huelva, Spain) with a $\mathrm{NaOH}$ solution and compared this with commercial lime putty of two grades, which showed a comparable indicator.

The study by Vinnichenko et al. [38] was based developing on $\beta$-hemihydrate obtained by roasting from phosphogypsum, dry building mixes for the manufacture of gypsum plaster, formulations for sealing joints and putty that satisfy all the necessary technological requirements.

Studies by Ma et al. [18] considered the possibility of manufacturing phosphogypsum (Hubei Yihua Fertilizer Inc., Hubei, China), a porous sound-absorbing material, based on $\beta$-hemihydrate obtained by low-temperature calcination $\left(160{ }^{\circ} \mathrm{C}\right)$. It is shown that with the following ratios of the components of the raw material mixture, by weight of the binder: pore-forming agent, $1 \%$ basalt fiber and $6 \%$ expanded perlite, it is possible to obtain a material that meets the requirements for the noise reduction coefficient of the Chinese standard (GB/T 16731-1997).

A group of researchers proved the possibility of obtaining stucco tiles - an analog of drywall [39-40]. As raw material, hemihydrate gypsum $\left(\mathrm{CaSO}_{4} \cdot 0.5 \mathrm{H}_{2} \mathrm{O}\right)$ obtained from phosphogypsum (Yichang City, Hubei Province, China) was used. In the first case [40], phosphogypsum was washed and dehydrated at a temperature of $150{ }^{\circ} \mathrm{C}$, moistened to obtain granules, and then repeated pressing was performed in an aqueous medium at a pressure of 20 $\mathrm{MPa}$ with a frequency of once every 2 minutes for 24 hours. The bending strength of the obtained tile was 18.9 $\mathrm{MPa}$. Second [40], phosphogypsum dehydration was carried out at a temperature of $170{ }^{\circ} \mathrm{C}$. The pressing duration is 3 hours, the frequency of application of the load is every 10 minutes and the bending strength of the obtained samples was $14.7 \mathrm{MPa}$.

The effectiveness of the semi-dry pressing method in the manufacture of products from unburned binders waste from ceramic industries (failed gypsum casting molds) was confirmed in numerous works by Petropavlovskaya et al. [41-44 and others].

Also, studies were conducted at the Ufa State Petroleum Technical University, Ufa, Russia [45] with the aim of considering the possibility of obtaining small-sized wall products and partition stones of products by pressing untreated phosphogypsum and its mixture with hemihydrate of calcium sulfate. The authors obtained a gypsum brick $250 \times 120 \times 65 \mathrm{~mm}$ in size, as well as a solid block wall block $120 \times 190 \times 590 \mathrm{~mm}$ with a compressive strength of 10.5 $\mathrm{MPa}$ (M100), and a wall block with a voidness of about $30 \%$, size $250 \times 120 \times 138 \mathrm{~mm}-5.4 \mathrm{MPa}(\mathrm{M} 50)$.

The method of semi-dry pressing at elevated pressures was used in the manufacture of articles [46, 47] from a mixture consisting of citrogypsum dehydrated at a temperature of $120-140{ }^{\circ} \mathrm{C}$ (Tsitrobel LLC, Belgorod, Russia) and perlite production wastes. The I/O ratio was taken as $0.18-0.19$. The molding was carried out in molds under a pressure of $10 \mathrm{MPa}$, with the aging of products at a specified pressure for 30 seconds. The compressive strength of the products in the dry state was 19-20 MPa [46]. In another case [47], pre-moistened sawdust was used as a filler, pressing was carried out at a pressure of $20 \mathrm{MPa}$, and the strength of the obtained sawdust concrete was 20-24 MPa.

Hua et al. [48] considered the possibility of using untreated phosphogypsum as a component of a grouting mixture containing also: grouting cement, ground granulated blast furnace slag, a complex of additives including silica fume, setting retarders, and water loss regulators (BXF200-L). During the phased selection, the composition was optimized so that in terms of compressive strength, linear expansion, porosity and permeability, the mixture meets the basic technical requirements for oil well cementing. Moreover, the hardened suspension of phosphogypsum, according to the authors, creates a significant expansion during hydration, and has an excellent ability to compensate for shrinkage. 
In addition to density, binders from GBW are used to produce heat and sound insulating materials. In particular, in [49] the authors consider the possibility of obtaining heat-insulating materials and plaster mortars. The three following types of multiphase gypsum systems (MGS) obtained from cytogypsum were used as a binder:

- based on insoluble anhydrite (AnII) and $\beta-\mathrm{CaSO}_{4} \cdot 0.5 \mathrm{H}_{2} \mathrm{O}$;

- based on AnII and $\beta$-dehydrated calcium sulfate hemihydrate;

- based on AnII and soluble anhydrite (AnIII).

Analyzing the results obtained during the research, the authors conclude that it is advisable to use separate grinding of the components upon receipt of the MHS, which can increase the compressive strength of the material in dry and water-saturated states by $24 \%$ and $85 \%$, respectively, and the softening coefficient by $48 \%$. At the same time, the necessity of using S-3 as a superplasticizer is indicated which, in contrast to lowering the physicomechanical characteristics of the final SB-3 products, contributes to their improvement. In particular, the compressive strength increases by $22 \%$, the gypsum ratio decreases by $30 \%$, and the $\mathrm{pH}$ decreases. Based on the results obtained on the optimization of MGS compositions and hardening conditions (steam-air medium), binders are given for stucco compositions and heat-insulating materials, where a sunflower husk is used as a filler.

The possibility of producing foam concrete by mixing phosphogypsum, a small amount of cement, blast furnace granulated slag, and quicklime pre-mixed with foam was shown in [50]. Varying the prescription and technological parameters revealed the optimal composition: phosphogypsum $45-55 \%$, quicklime $4 \%$; sulfoaluminate cement $2 \%$, the rest is cement and blast furnace granulated slag in a ratio of $1: 1$; optimum W/T $0.4-0.5$. Moreover, while most phosphogypsum acted as a filler, a small part participated in the formation of ettringite. The materials obtained in terms of density and thermal conductivity fully met the requirements of the relevant Chinese standards.

The possibility of using phosphogypsum (Yunnan phosphate fertilizer plant, China) as a part of the mixture (cement $15 \%$, ground granulated blast furnace slag $30 \%$, phosphosypsum $55 \%$, hydrated lime $7 \%, \mathrm{Na}_{2} \mathrm{SO}_{4} 1.6 \%$, aluminum powder $0.074 \%$, W/T 0.45 , the optimum steaming temperature is $90{ }^{\circ} \mathrm{C}$ ) for the production of nonautoclaved aerated concrete was shown in [51]. The authors note that phosphogypsum will play the role of not only a filler, but also an activator, while the resulting aerated concrete meets the requirements of Chinese standards in terms of strength, frost resistance and thermal conductivity. However, the solution to the problem of shrinkage regulation requires further study.

The authors of [52] considered the possibility of using phosphogypsum (Fertiberia plant, Ulva, Spain) as a component of sulfur-polymer concrete. It was found that with a sulfur/phosphogypsum ratio $=1: 0.9$ and a phosphogypsum content in the mixture $=10-40 \mathrm{wt} . \%$, it is possible to obtain concrete samples with a strength of 54-62 MPa and a total porosity of $2.8-6.8 \%$. At the same time, the authors note that the developed materials comply with the requirements for radiological safety and can be used without restrictions.

\subsection{Alkaline-activated binders}

In the production of alkali-activated binders (geopolymers), gypsum-bearing wastes, in particular phosphogypsum, showed good results as a component of the mixture [53-56]. Hence, in [53] it was shown that the use of phosphogypsum helps to reduce the activation time of cinder-alkaline binder hardening at room temperature. In particular, its $5 \%$ content in the mixture contributes to a $29 \%$ increase in strength. Moreover, after high-temperature exposure $\left(800^{\circ} \mathrm{C}\right)$, the residual strength of such samples is 1.2 times higher in comparison with the control made without phosphogypsum. Similar results were obtained in [54], according to which the replacement of fly ash by 5 and $10 \%$ phosphogypsum accelerates the activation process and increases the strength of samples, while the residual strength after high-temperature exposure of samples with 5\% phosphogypsum content is 2.1 times and with $10 \%$ phosphogypsum content is 1.7 times higher than this indicator for control non-supplemented samples. This gave the authors the basis to conclude that the use of such materials is promising in cases where it is necessary to provide increased fire resistance.

Two studies $[55,56]$ also demonstrated the possibility of using phosphogypsum in the production of supersulfated cement (SSC) which included [56] up to $81 \%$ of crushed granulated blast furnace slag, $15 \%$ phosphogypsum, $3 \%$ Portland cement clinker, and 1\% aluminate cement as a setting accelerator. In both studies, conventional phosphogypsum was used, as well as being modified in two ways: fired at a temperature of $500{ }^{\circ} \mathrm{C}$ and neutralized by adding 4\% lime. An analysis of the results showed that calcined phosphogypsum delays early hydration and prolongs the incubation period, while neutralized phosphogypsum accelerates these. Control samples were characterized by very slow early hydration. In this case, an increase in the strength of all samples was observed, especially with age in the range of 28 to 90 days. However, this effect for samples with calcined phosphogypsum manifests itself in a later period. Also revealed were an improvement in the microstructure of all samples, a decrease in their 
porosity, as well as stabilization of the formation of ettringite to a greater extent when using calcined phosphogypsum.

In [56], the influence of the temperature $\left(150{ }^{\circ} \mathrm{C}, 350{ }^{\circ} \mathrm{C}, 600^{\circ} \mathrm{C}, 800{ }^{\circ} \mathrm{C}\right)$ and the calcination time $(0.5 \mathrm{~h}, 1 \mathrm{~h}$, $1.5 \mathrm{~h}, 2 \mathrm{~h}$ ) of phosphogypsum on the properties of SSC were investigated. The authors concluded that calcination, especially at high temperatures, significantly reduced the negative effect of impurities contained in phosphogypsum on the properties of SSC. Samples containing phosphogypsum, which was calcined for 2 hours at a temperature of $600{ }^{\circ} \mathrm{C}$, differed in the best strength indices. In this case, samples with phosphogypsum, which was calcined at 350 ${ }^{\circ} \mathrm{C}$ for 2 hours, were characterized by fast setting.

\subsection{Ceramic materials}

Another area of use of gypsum-bearing wastes is the ceramic industry. In particular, in [57] the results of the influence of borogypsum (Emet, Turkey), which was introduced into the study in an amount of up to $15 \%$, on the properties of ceramic bricks are presented. An analysis of the results showed that the introduction of $10 \%$ of this gypsum-bearing wastes reduces the average density by $2.46-16.47 \%$, increases the compressive strength and aesthetic expressiveness of ceramic bricks, because borogypsum acts as a bleaching additive.

A study of the possibility of using phosphogypsum in the production of building ceramics was carried out in [58]. The main goal was to establish the technical feasibility of using fly ash and phosphogypsum in the production of ceramic bricks. During the research, part of the clay was replaced with technogenic raw materials in seven weight proportions of $0 \%, 5 \%, 10 \%, 15 \%, 20 \%, 25 \%$ and $3 \%$. All samples were calcined at a temperature of 1000 ${ }^{\circ} \mathrm{C}$. An analysis of the results showed that replacing part of the clay with phosphogypsum increases the density of bricks, compressive strength and helps to reduce water absorption.

In [59], the authors presented the results of studies aimed at considering the possibility of obtaining ceramic tiles. Phosphogypsum (Ulva, Spain) was introduced into clay in an amount of 5; 7.5 and $10 \%$ by weight andfiring was carried out at temperatures of $950,1050,1150{ }^{\circ} \mathrm{C}$. Analyzing the results, the authors conclude that the content of the mixture up to $7.5 \%$ phosphogypsum positively affects the characteristics of the final products; in some cases the bending strength exceeds the performance of the control samples. Also, the introduction of phosphogypsum, characterized by increased dispersion, reduces the linear shrinkage of the samples during the firing process.

Vasilenko and Ali [60] investigated the possibility of producing expanded clay gravel with the use of defecate and citrogypsum additives in an amount of 1.0-9.0\%, as well as their effect on the physicomechanical characteristics and the glass phase content in expanded clay. The authors found that the content of the investigated waste in expanded clay should not exceed $4.0 \%$ at a set optimal firing temperature of $1150{ }^{\circ} \mathrm{C}$. The bulk density of the obtained samples was $0.29-0.31 \mathrm{t} / \mathrm{m}^{3}$, and the compressive strength was $0.54-0.68 \mathrm{MPa}$. The brand of the obtained samples with the addition of defecate in strength corresponds to P25, for cytogypsum to P35 and P25, and in bulk density, respectively, to grades 300 and 350 .

\subsection{Road construction}

In addition to the traditional applications for hemihydrate and gypsum binders, phosphogypsum is considered in some studies as raw materials in road construction. In particular, Amrani et al. [61] studied the possibility of using phosphogypsum (P) as the material for a highway embankment, as well as the effect of stabilizers such as clay soil (CS), fly ash (FA), lime (L), and calcareous material (CM) on the embankment) and a special hydraulic road binder (HRB). The task was to increase strength to a threshold value that allows the use of a stabilized mixture as the main material in the road surface, while ensuring neutralization of the acidity of phosphogypsum. Their studies showed that when using phosphogypsum in its pure form, the height of the embankment should be less than $4 \mathrm{~m}$. A mixture of phosphogypsum with clay soil at a ratio of $\mathrm{P}: \mathrm{FA}=40: 60$ was distinguished by good indicators of resistance to immersion, bearing ability and compaction characteristic, and this mixture also successfully passed tests under the influence of compressive loads. The height of such an embankment can be increased to $8 \mathrm{~m}$. In addition, the authors found that the mixture (CM:P:FA):HRB $=(10: 25: 65): 7$ can be used for paving (base and base layer).

Shen et al. [62] considered a raw mix - fly ash - for steel paving: steelmaking slag $=1: 1$, dosage of phosphogypsum $=2.5 \%$. The study of the properties of the obtained material showed that its 28-day and 360-day strengths are $8 \mathrm{MPa}$ and $12 \mathrm{MPa}$, respectively, the elastic modulus reaches $1987 \mathrm{MPa}$, and the splitting strength is $0.82 \mathrm{MPa}$. Moreover, the material has a higher early strength than the calcareous and calcareous soil base, its tensile strength under long-term load is much higher than that of cement-reinforced soil, and the material also has better water resistance compared to those materials listed above.

Folek et al. [63] proved the possibility of using a three-component mixture of phosphogypsum-ash-slag for the device of the upper layers of a road embankment and pavement base. 
Cuadri et al. [64] showed that the introduction of 10\% phosphogypsum (Panreac, Spain), treated with a small amount of sulfuric acid $(0.5 \mathrm{wt}$ \%) at high temperatures significantly improves the rheological characteristics of bitumen used in highway construction.

The possibility of using phosphogypsum in highway construction has also been confirmed by Russian researchers whereby Kochetkov et al. [65] studied the feasibility of using calcium sulfate hemihydrate for construction, reconstruction and repair of highways and Gerasimov et al. [66] studied the feasibility of using dried phosphogypsum as a component of granular asphalt mix.

Based on the data obtained, as an intermediate result, a general scheme of application areas for gypsum-bearing waste was developed (Fig. 1).

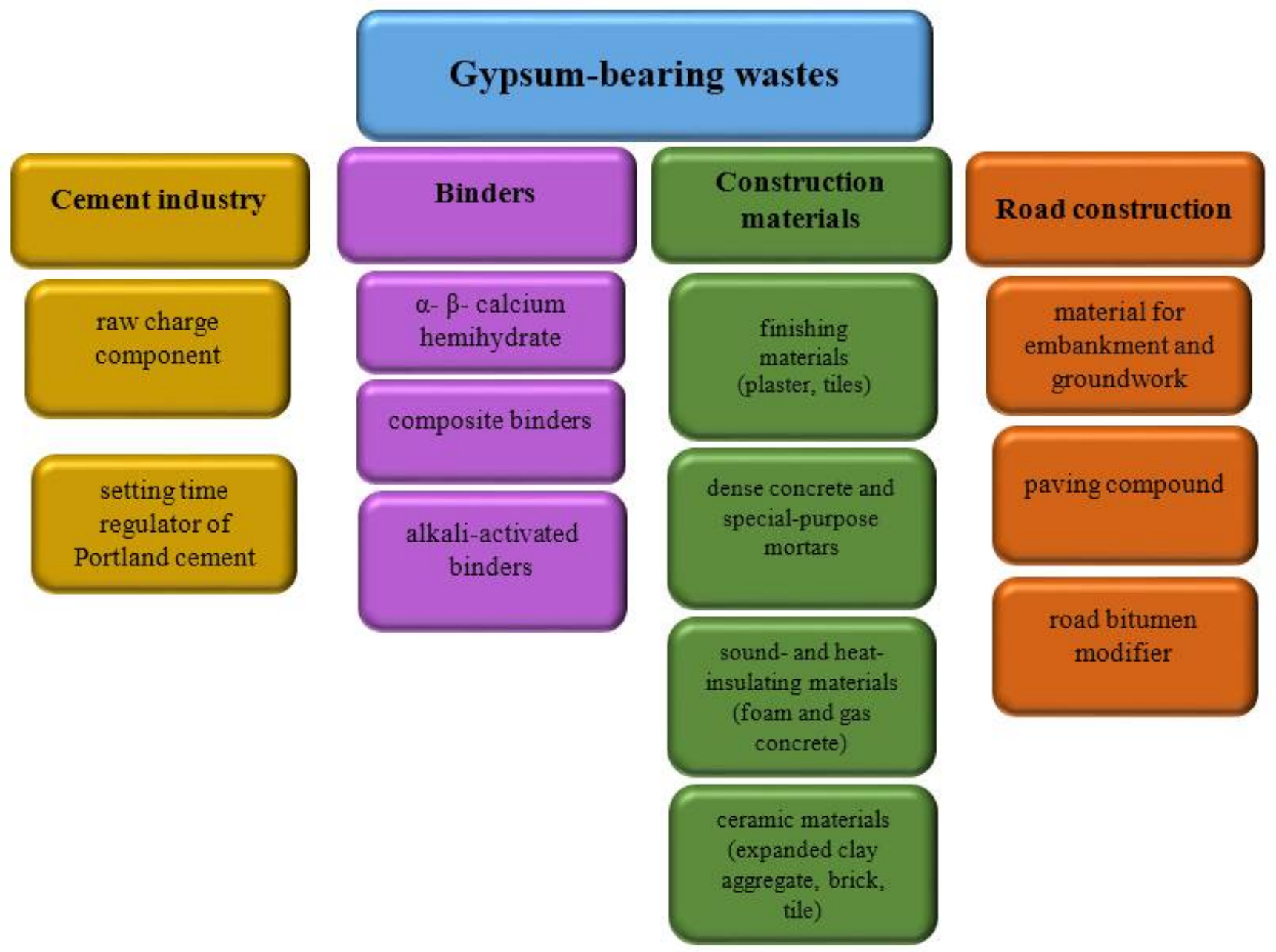

Fig 1. Application areas for GBW

\section{Conclusions}

Based on this literature review, the following main conclusions can be drawn.

The mastered area of application of gypsum-bearing wastes is very diverse, and among the main areas we can distinguish the cement industry (production of cement clinker, additives for cement setting retarders), production of single and multicomponent gypsum binders and products based on them, production of dense, as well as sound and heat insulation solutions, use in the ceramic industry and in road construction.

The use of standard technologies in the processing of natural gypsum stone into binders, in the case of using gypsum-bearing wastes, as a rule, is not effective. This is due to a number of GBW features: first, increased humidity, instability of the material composition and the presence of a large amount of impurities; second, high dispersion of raw materials. All these factors affect the quality of the final product and require the development of additional measures to solve these problems - the search for ways to clean or make changes to technological modes need further research.

Among the considered methods for the synthesis of binders from gypsum-bearing wastes, three main methods can be distinguished - autoclave treatment, calcination and the chemical method (salt solutions, sulfuric acid). Each 
of the methods has variations and a number of advantages and disadvantages; however, it does not allow to organize a cost-effective production of binders in industrial volumes.

Gypsum-bearing wastes in its natural and processed forms can be considered not only from the standpoint of the need for their disposal, but also as a valuable raw material, which allows to improve the quality characteristics or to give special properties to the final products.

The most effective way of forming small-sized pieces based on binders obtained from gypsum-bearing raw materials is semi-dry pressing and pressing in an aqueous medium which, unlike injection technology, makes it easier and cheaper to obtain products with high strength indicators.

Among gypsum-bearing wastes, phosphogypsum has the greatest application in the building materials industry, which is determined by its large tonnage and wide distribution around the world. However, the content of a large number of impurities in its composition, including radioactivity, does not make it possible to consider it as an alternative to natural gypsum stone. Using it as a raw material for the production of binders or pieces (plates, blocks, etc.) is associated with the need to clean it of dangerous impurities, which significantly affects the cost of the final products. At the same time, its use as an additive in limited quantities does not noticeably affect the radiation safety of the final product. However, this approach does not ensure the involvement of a large amount of waste and is not able to provide a solution to the disposal problem as a whole.

The current level of research on the issue as a whole is not exhaustive. All examined gypsum-bearing wastes have great potential as objects of further study in order to improve existing and search for new and more efficient methods regarding their processing and use.

\section{Acknowledgments}

Work realized within the framework of the project "Creation of a complex technology for recycling gypsumcontaining waste of industrial enterprises", that is implemented on the platform of the Belgorod Scientific and Educational Center of the world level "Innovative Solutions in the Agricultural Sector"

\section{References}

1. Plaster materials and products (production and use). Directory. Ferronskaya A.V., Publishing House ASV, Russian Federation, 2004. 488 p.

2. Mineral Commodity Summaries, 2021. Department of the Interior, U.S. Geological Survey. P. $122-123$. https://pubs.usgs.gov/periodicals/mcs2021/mcs2021.pdf

3. Rashad A.M. Phosphogypsum as a construction material. Journal of Cleaner Production. 2017. 166. P. 732 743. doi:10.1016/j.jclepro.2017.08.049

4. Tayibi H., Choura M., Lo'pez F.A., Alguacil F.J., Lo'pez-Delgado A. Environmental impact and management of phosphogypsum. Journal of Environmental Management. 2009. 90 (8). P. 2377 - 2386. https://doi.org/10.1016/j.jenvman.2009.03.007

5. Huang Y., Qian J., Kang X., Yu J., Fan Y., Dang Y., Zhang W., Wang, S. Belite-calcium sulfoaluminate cement prepared with phosphogypsum: Influence of $\mathrm{P}_{2} \mathrm{O}_{5}$ and $\mathrm{F}$ on the clinker formation and cement performances. Construction and Building Materials. 2019. 203. P. 432 - 442. https://doi.org/10.1016/j.conbuildmat.2019.01.112

6. Kacimi L., Simon-Masseron A., Ghomari A., Derriche Z. Reduction of clinkerization temperature by using phosphogypsum. Journal of Hazardous Materials. 2006. 137. P. 129 - 137. doi:10.1016/j.jhazmat.2005.12.053

7. Islam G.M.S., Chowdhury F.H., Raihan M.T., Amit S.K.S., Islam M.R. Effect of Phosphogypsum on the Properties of Portland Cement. Procedia Engineering. 2017. 171. P. 744 - 751. https://doi.org/10.1016/j.proeng.2017.01.440

8. Huang Y., Qian J., Lu L., Zhang W., Wang S., Wang W., Cheng, X. Phosphogypsum as a component of calcium sulfoaluminate cement: Hazardous elements immobilization, radioactivity and performances. Journal of Cleaner Production. 2020. 2481. 119287. https://doi.org/10.1016/j.jclepro.2019.119287

9. Taher M.A. Influence of thermally treated phosphogypsum on the properties of Portland slag cement. Resources, Conservation and Recycling. 2007. 52 (1). P. 28 - 38. https://doi.org/10.1016/j.resconrec.2007.01.008

10. Ozkul M.H. Utilization of citro- and desulphogypsum as set retarders in Portland cement. Cement and Concrete Research. 2000. 30. P. 1755 - 1758. https://doi.org/10.1016/S0008-8846(00)00409-9

11. Bensted J. Early hydration behaviour of portland cement containing boro-, citro- and desulphogypsum. Cement and Concrete Research. 1980. 10 (2). P. 165 - 171. https://doi.org/10.1016/0008-8846(80)90073-3

12. Elbeyli İ.Y., Derun M., Gülen J., Pişkin S. Thermal analysis of borogypsum and its effects on the physical properties of Portland cement. Cement and Concrete Research. 2003. 33 (11). P. 1729 - 1735. https://doi.org/10.1016/S0008-8846(03)00110-8 
13. Sevim U.K., Tumen Y. Strength and fresh properties of borogypsum concrete. Construction and Building Materials. 2013. 48. P. 342 - 347. http://dx.doi.org/10.1016/j.conbuildmat.2013.06.054

14. Yang J., Liu W., Zhang L., Xiao B. Preparation of load-bearing building materials from autoclaved phosphogypsum. Construction and Building Materials. 2009. 23. $\quad$ P. 687 - 693 . https://doi.org/10.1016/j.conbuildmat.2008.02.011

15. Myasnikov N.F., Bershakov N.G., Kozlov V.P., Naumov E.G., Shevchenko N.N. Gypsum binder preparation method. Patent RF, no. 2210540, 2003.

16. Semlyov V.S., Reutov V.A., Kondrikov N.B. Method of recycling gypsiferous raw materials. Patent RF, no. $2324654,2008$.

17. Gubskaya A.G., Podluzsky E.Ya., Melenko V.S. Production of gypsum binder and products from natural and industrial raw materials in the Republic of Belarus. Building Materials. 2018. 3. P. 73 - 75. (rus.)

18. Ma B., Jin Z., Su Y., Lu W., Qi H., Hu P. Utilization of hemihydrate phosphogypsum for the preparation of porous sound absorbing material. Construction and Building Materials. 2020. 234.117346. https://doi.org/10.1016/j.conbuildmat.2019.117346

19. Li X., Zhang Q., Ke B., Wang X., Li L., Li X., Mao S. Insight into the effect of maleic acid on the preparation of a-hemihydrate gypsum from phosphogypsum in $\mathrm{Na}_{2} \mathrm{SO}_{4}$ solution. Journal of Crystal Growth. 2018. 493. P. 34 - 40. https://doi.org/10.1016/j.jcrysgro.2018.04.025

20. Li X., Zhang Q., Shen Z., Li L., Li X., Ma S. L-aspartic acid: A crystal modifier for preparation of hemihydrate from phosphogypsum in $\mathrm{CaCl}_{2}$ solution. Journal of Crystal Growth. 2019. 511. P. 48 - 55. https://doi.org/10.1016/j.jcrysgro.2019.01.027

21. Lu W., Ma B., Su Y., He X., Jin Z., Qi H. Preparation of a-hemihydrate gypsum from phosphogypsum in recycling $\mathrm{CaCl}_{2}$ solution. Construction and Building Materials. 2019. 214. P. 399 - 412 . https://doi.org/10.1016/j.conbuildmat.2019.04.148

22. Ma B., Lu W., Su Y., Li Y., Gao C., He X. Synthesis of a-hemihydrate gypsum from cleaner phosphogypsum. Journal of Cleaner Production. 2018. 195. 396e405 https://doi.org/10.1016/j.jclepro.2018.05.228

23. Guan B., Yang L., Wu Z., Shen Z., Ma X., Ye Q. Preparation of $\alpha$-calcium sulfate hemihydrate from FGD gypsum in $\mathrm{K}$, Mg-containing concentrated $\mathrm{CaCl}_{2}$ solution under mild conditions. Fuel. 2009. 88. P. 1286 - 1293. doi:10.1016/j.fuel.2009.01.004

24. Shen Z.X., Guan B.H., Fu H.L., Yang L. Effect of Potassium Sodium Tartrate and Sodium Citrate on the Preparation of a-Calcium Sulfate Hemihydrate from Flue Gas Desulfurization Gypsum in a Concentrated Electrolyte Solution. J. Am. Ceram. Soc., 2009. 92 (12). P. 2894 - 2899. doi:10.1111/j.1551-2916.2009.03330.x

25. Guan B., Kong B., Fu H., Yu J., Jiang G., Yang L. Pilot scale preparation of a-calcium sulfate hemihydrate from FGD gypsum in $\mathrm{Ca}-\mathrm{K}-\mathrm{Mg}$ aqueous solution under atmospheric pressure. Fuel. 2012. 98. P. 48 - 54. http://dx.doi.org/10.1016/j.fuel.2012.03.032

26. Tarasova G.I., Sverguzova S.V., Bubnova N.Yu., Kozlov V.P., Naumov E.G. Method of gypsum article making. Patent RF, no. 2132310, 1999.

27. Sverguzova S.V., Tarasova G.I., Bubnova N.Yu. Promising technologies for the processing of citrogypsum. Ecology and industry of Russia. 1998. 8. P. 20 - 24. (rus.)

28. Sverguzova S.V., Bubnova N.Yu., Tarasova G.I. Utilization of gypsum-bearing waste by energy-saving technology. Scienc-product. 2001. 3. P. 41 - 43. (rus.)

29. Sverguzova S.V., Chernysheva N.V., Chernysh L.I., Shamshurov A.V. The in-fluence of the processing conditions of citrogyp-sum on the composition of the obtained gypsum binder. Building Materials. 2010. 7. P. 31 32. 9 (rus.)

30. Sverguzova S.V., Tarasova G.I., Chernysheva N.V., Chernysh L.I. Theoretical substantiation of the possibility of non-fired de-hydration of citrogypsum. Bulletin of BSTU named after V.G. Shukhov. 2010. 2. P. 117 - 121. (rus.)

31. Chernysheva N.V., Sverguzova S.V., Tarasova G.I. Obtaining a gypsum binder from phosphogypsum of Tunisia. Building Materials. 2010. 7. P. 28 - 30. (rus.)

32. Alfimova N.I., Pirieva S.Yu., Elistratkin M.Yu., Kozhuhova N.I., Titenko A.A. Production methods of binders containing gypsum-bearing wastes: a review. Bulletin of BSTU named after V.G. Shukhov. 2020. 11. P. 8 - 23. doi: 10.34031/2071-7318-2020-5-11-8-23 (rus.)

33. Jin Z., Ma Baoguo, Su Y., Lu W., Qi H., Hu P. Effect of calcium sulphoaluminate cement on mechanical strength and waterproof properties of beta-hemihydrate phosphogypsum. Construction and Building Materials. 2020. 242. 118198. https://doi.org/10.1016/j.conbuildmat.2020.118198 
34. Yang L., Zhang Y., Yan Y. Utilization of original phosphogypsum as raw material for the preparation of self-leveling mortar. Journal of Cleaner Production. 2016. 127. P. 204 - 213. http://dx.doi.org/10.1016/j.jclepro.2016.04.054

35. Chernysh L.I. Improving the efficiency of building composites obtained using industrial waste. Ecology and industry. 2014. 4. P. $87-89$. (rus.)

36. Lukyanova A.N., Starostina I.V. Building composite materials based on modified gypsum binders obtained from industrial wastes. Fundamental research. 2013. 4 (4). P. 818 - 822. (rus.)

37. Romero-Hermida M.I., Borrero-López A.M., Alejandre F.J., Flores-Alés V., Santos A., Franco J.M., Esquivias L. Phosphogypsum waste lime as a promising substitute of commercial limes: A rheological approach. Cement and Concrete Composites. 2019. 95. P. 205 - 216. https://doi.org/10.1016/j.cemconcomp.2018.11.007

38. Vinnichenko V.I., Kostyuk T.A., Mokrenko N.N., Ivaschenko T.G. The possibility of obtaining building materials based on phosphogypsum. Dry Build. Mixes. 2014. 3. P. 18 - 19. (rus.)

39. Zhou J., Sheng Z., Li T., Shu Z., Wang Y. Preparation of hardened tiles from waste phosphogypsum by a new intermittent pressing hydration. Ceramics International. 2016. 42 (61). P. 7237 - 7245 https://doiorg.ezproxy.libfl.ru/10.1016/j.ceramint.2016.01.117

40. Zhou J., Li X., Zhao Y., Shu Z., Wang Y., Zhang Y., Shen X. Preparation of paper-free and fiber-free plasterboard with high strength using phosphogypsum. Construction and Building Materials. 2020. 243. 118091. https://doi.org/10.1016/j.conbuildmat.2020.118091

41. Petropavlovskaya V.B., Belov V.V., Novichenkova T.B., Buryanov A.F., Poleonova Yu.Yu., Petropavlovsky, K.S. Resource-saving non-fired gypsum composites. Building Materials. 2015. 6. P. 79 - 81. (rus.)

42. Petropavlovskaya V.B.; Novichenkova T.B.; Buryanov A.F. Improving the technological properties of nonfired hyper-pressed gypsum products. Bulletin of BSTU named after V.G. Shukhov. 2013. 6. P. 75 - 78. (rus)

43. Petropavlovskaya V.B., Buryanov A.F., Novichenkova T.B., Poleonova Yu.Yu. About the effect of nanofillers on the properties of non-fired gypsum composites. Actual problems of modern science, technology and education. 2013. Vol. 2. 71. P. 217 - 220. (rus.)

44. Petropavlovskaya V.B. Low-energy gypsum materials and products based on industrial waste. Building Materials. 2006. 7. P. 8 - 9. (rus.)

45. Mirsaev R.N., Babkov V.V., Nedoseko I.V., Yunusova S.S., Akhmadulina I.I., Shayakhmetov U.S. Structural formation and hardening of pressed compositions based on calcium sulfate dehydrate. Building Materials. 2009. 6. P. 6 - 9. (rus.)

46. Alfimova N.I., Titenko A.A., Nikulin I.S., Galdun Yu.V., Pirieva S.Yu., Elistratkin M.Yu. Raw mixture for modified citrogypsum articles and method of their production. Patent RF, no. 2693808, 2018.

47. Alfimova N.I., Titenko A.A., Nikulin I.S., Galdun Yu.V., Pirieva S.Yu., Chepurnyh, A.A. Raw mix for sawdust concrete and a method of manufacturing products from sawdust concrete. Patent RF, no. 2695313, 2018.

48. Hua S., Wang K., Yao X. Developing high performance phosphogypsum-based cementitious materials for oil-well cementing through a step-by-step optimization method. Cement and Concrete Composites. 2016. 72. P. 299 - 308. https://doi.org/10.1016/j.cemconcomp.2016.05.017

49. Edamenko A.S., Klimenko V.G. About possible use man-made raw materials in production of construction materials. Internet magazine "Technosphere Safety Technologies". 2013. 1. http://agps-2006.narod.ru/ttb/20131/06-01-13.ttb.pdf (rus)

50. Tian T., Yun Y., Hu Z.H., Chen Y., Shi J. Utilization of original phosphogypsum for the preparation of foam concrete. Constr. Build. Mater. 2016. 115. P. 143 - 152. https://doi.org/10.1016/j.conbuildmat.2016.04.028

51. Yang L., Yan Y., Hu Z. Utilization of phosphogypsum for the preparation of non-autoclaved aerated concrete. Construction and Building Materials. 2013. 4. P. $600-606$. http://dx.doi.org/10.1016/j.conbuildmat.2013.03.070

52. López F.A., Gázquez M., Alguacil F.J., Bolívar J.P., García-Díaz I., López-Coto I. Microencapsulation of phosphogypsum into a sulfur polymer matrix: physico-chemical and radiological characterization. Journal of Hazardous Materials. 2011. 192. P. 234 - 245. doi:10.1016/j.jhazmat.2011.05.010

53. Vaic`iukyniene D., Nizevic`iene` D., Kiele` A., Janavic`ius E., Pupeikis D. Effect of phosphogypsum on the stability upon firing treatment of alkali-activated slag. Construction and Building Materials. 2018. 184. P. $485-$ 491. https://doi.org/10.1016/j.conbuildmat.2018.06.213

54. Rashad A.M. Potential use of phosphogypsum in alkali-activated fly ash under the effects of elevated temperatures and thermal shock cycles. Journal of Cleaner Production. $2015.87 .717 \mathrm{e} 725$. http://dx.doi.org/10.1016/j.jclepro.2014.09.080 
55. Liu S., Wang L., Yu B. Effect of modified phosphogypsum on the hydration properties of the phosphogypsum-based supersulfated cement. Construction and Building Materials. 2019. 21430. P. 9 - 16 https://doi.org/10.1016/j.conbuildmat.2019.04.052

56. Liu S., Ouyang J., Ren J. Mechanism of calcination modification of phosphogypsum and its effect on the hydration properties of phosphogypsum-based supersulfated cement. Construction and Building Materials. 2020. 24320. 118226

57. Emrullahoglu Abi C.B. Effect of borogypsum on brick properties. Construction and Building Materials. 2014. 59. P. 195 - 203. http://dx.doi.org/10.1016/j.conbuildmat.2014.02.012

58. Türkel S., Aksin E. A comparative study on the use of fly ash and phosphogypsum in the brick production. Sadhana. 2012. 37. P. 595 - 607. https://doi.org/10.1007/s12046-012-0099-8

59. Contreras M., Teixeira S.R., Santos G.T.A., Gázquez M.J., Romero M., Bolívar J.P. Influence of the addition of phosphogypsum on some properties of ceramic tiles. Construction and Building Materials. 2018. 17530. P. 588 - 600. https://doi.org/10.1016/j.conbuildmat.2018.04.131

60. Vasilenko T.A., Ali Saleh-Jafer Physical and mechanical properties of expanded clay gravel obtained using calcium-containing technogenic materials. Modern problems of science and education. 2015.1-2. Available online: http://science-education.ru/ru/article/view?id=19899 (accessed on 04.05.2020). (rus.)

61. Amrani M., Taha Y., Kchikach A., Benzaazoua M., Hakkou R. Phosphogypsum recycling: New horizons for a more sustainable road material application. Journal of Building Engineering. 2020. 101267 https://doi.org/10.1016/j.jobe.2020.101267

62. Shen W., Zhou M., Ma W., Hub J., Cai, Z. Investigation on the application of steel slag-fly ashphosphogypsum solidified material as road base material. Journal of Hazardous Materials. 2009. 164. P. 99 - 104. doi:10.1016/j.jhazmat.2008.07.125

63. Folek S., Walawska B., Wilczek B., Mioekiewicz J. Use of phosphogypsum in road construction. Journal of Building Engineering. 2011.13 (2). P. 18 - 22. doi:10.2478/v10026-011-0018-5

64. Cuadri A.A., Navarro F.J., García-Morales M., Bolívar J.P. Valorization of phosphogypsum waste as asphaltic bitumen modifier. Journal of Hazardous Materials. 2014. 27930. P. $11 \quad-\quad 16$ https://doi.org/10.1016/j.jhazmat.2014.06.058

65. Kochetkov A.V., Shchegoleva N.V., Korotkovskij S.A., Talalaj V.V., Vasil'ev Yu.E., Shashkov I.G. The device layers of transport structures from phosphogypsum hemihydrate (waste by-product of the production of nitrogen-phosphorus fertilizers). Internet magazine "Transport facilities"2019. $1 . \quad \mathrm{https} / / \mathrm{t}$ s.today/PDF/18SATS119.pdf, doi: 10.15862/18SATS119 (rus.)

66. Gerasimov D.V., Ignatiev A.A., Gotovtsev V.M., Golikov I.V. Prospects for the use of phosphogypsum in the production of asphalt concrete. Roads and Bridges.2018. 40. P. $304-315$. (rus.)

For citation:. Alfimova N.I., Pirieva S.Yu., Titenko A.A. Utilization of gypsum-bearing wastes in materials of the construction industry and other areas. Construction Materials and Products. 2021. 4 (1). P. 5 - 17. DOI: $10.34031 / 2618-7183-2021-4-1-5-17$

Поступила в редакциию 20 декабря 2020 г.

Принята в доработанном виде 15 января 2021 г.

Одобрена для публикаџии 3 февраля 2021 г.
Received: December 20, 2020.

Revised: January 15, 2021.

Accepted: February 3, 2021. 